\title{
Múltiplos olhares sobre a mortalidade infantil no Ceará, Brasil
}

\author{
Multiple perceptions of infant mortality \\ in Ceará State, Brazil
}

1 Faculdade de Medicina,
Universidade Federal do
Ceará, Fortaleza, Brasil.
2 Programa de Pós-graduação
em Saúde Coletiva,
Universidade de Fortaleza,
Fortaleza, Brasil.
Correspondência
J. R. P. Sousa
Departamento de Saúde
Comunitária, Faculdade
de Medicina, Universidade
Federal do Ceará.
Rua Costa Mendes 1608,
5o andar, Fortaleza, CE
60430-140, Brasil.
joserobertopereira@yahoo.
com.br

Abstract

This qualitative study analyzes the perceptions of various social actors towards infant mortality and the program to reduce it in Ceará State, Northeast Brazil. The study compares two municipalities (counties) that showed opposite infant mortality trends from 1993 to 1997, during which time Ceará achieved international visibility for having reduced infant mortality statewide. A total of 48 semi-structured interviews with four groups of key informants - health system managers, community health agents, mothers who had lost a child, and neighbor women with children in the same age bracket - and content analysis revealed "multiple conflicting voices" on the issue. Although the level of political determination to implement the interventions varied between the two municipalities, the differences in perceptions concerning infant death were more striking between the various groups of social actors, regardless of the municipality. The study revealed a kind of authoritarian educational practice that jeopardizes acceptance of the Community Health Agents Program. Public policies are needed that give voice to the people closest to the experience of infant death.

Infant Mortality; Health Education; Health Policy; Program Development; Anthropology
José Roberto Pereira de Sousa 1 Marilyn Nations ${ }^{2}$

\section{Introdução}

O Estado do Ceará tem chamado a atenção nacional e internacional pela luta contra a mortalidade infantil, recebendo do Fundo das Nações Unidas para a Infância (UNICEF) o Prêmio Maurice Pate ${ }^{1}$. Apesar da pobreza, doenças infecciosas, exclusão social 2 , violência hospitalar ${ }^{3}$ e, até, homicídios de mulheres 4 , a taxa de mortalidade infantil diminuiu drasticamente de 166/1.000 nascidos vivos no final de 19605 para $16,2 \mathrm{em}$ 20076 . Sendo a maior queda entre 1991 e 1997 redução maior que $66 \%$ 6,7.

Poucos trabalhos, timidamente, apontam hipóteses para explicar a redução da taxa de mortalidade infantil no Ceará 7,8, não esgotando a complexidade dos fatores envolvidos. Na literatura científica nacional encontramos alguns destes prováveis determinantes: a implantação do Programa de Agentes Comunitários de Saúde (PACS), a implantação do Programa Saúde da Família (PSF), alterações no financiamento da atenção básica, as estratégias das políticas de saúde, campanhas de mídia em massa, as competências culturais das mães empobrecidas e combate à desidratação pelas rezadeiras 7,8,9,10,11.

Pesquisa realizada entre 1990 e 1998 evidenciou uma significativa diferença do decréscimo da taxa de mortalidade infantil entre as capitais brasileiras, revelando brechas redutiveis de mortalidade 12. No Ceará, de 1993-1997, também foi 
significativa a diferença do declínio na taxa de mortalidade infantil entre municípios que, antes, tinham população e perfil socioeconômico semelhantes; uns conseguiram uma redução > que $60 \%$, enquanto outros não atingiram $15 \%$ de redução 7,13 .

Serapioni 14 sugere a pesquisa qualitativa para melhor compreensão de processos importantes na redução da mortalidade infantil. Optou-se, portanto, por uma pesquisa qualitativa, apoiada na análise das múltiplas visões - a multivocalidade - dos diversos agentes sociais 15,16. Procurou-se ir além das explicações quantitativas - das "metas" e "taxas" - enxergando pelo olhar crítico daqueles que vivenciaram a queda na taxa de mortalidade infantil, uns distantes e outros mais próximos dessa dura realidade.

Buscou-se, com efeito, descrever e analisar as múltiplas concepções sobre a mortalidade infantil e as políticas desenvolvidas em dois municípios do Ceará que apresentaram resultados opostos na redução deste indicador entre 1993 e 1997.

\section{Desvendar os múltiplos olhares}

Esta pesquisa, com uma abordagem qualitativa, procura descrever e analisar as concepções de profissionais de saúde, gestores e usuários sobre a redução da morte precoce. Embora não se trate de uma pesquisa estratégica, na concepção de Minayo 17, expõe aspectos importantes das políticas de saúde. Elegemos o período de fevereiro de 1993 a fevereiro de 1997 por dois motivos: englobar uma gestão municipal completa e estar dentro das décadas de maior redução taxa de mortalidade infantil no Ceará 6,18. Dentre os municípios que tinham dados no Sistema de Informação do Programa Agente de Saúde (SIPAS) - melhor sistema de informação da época 19 e com > 500 nascimento/ano, escolhemos dois municípios; sendo um dentre os 10 de maior redução da taxa de mortalidade infantil e o outro dentre os 10 de menor redução dessa taxa.

O município com maior êxito chamou-se de (Ma), cuja taxa de mortalidade infantil que era 106/1.000, em 1993, reduziu para 36/1.000 nascidos vivos em 1997. Localizada a 125 quilômetros da capital estadual, Fortaleza, (Ma) tinha 33.645 habitantes em 1993, com 43,6\% morando na zona rural; $34,2 \%$ dos chefes de família ganhavam < 1/2 salário mínimo. O município com redução, no mesmo período, de apenas 77 para $68 / 1.000$ nascidos vivos, chamou-se de (Mb). Localizado a 295 quilômetros de Fortaleza, tinha, em 1993, 35.099 habitantes; $63,2 \%$ residindo na zona rural; $32,4 \%$ dos chefes ganhavam $<1 / 2$ salário mínimo.
De abril a julho de 1998, foram realizadas 48 entrevistas; compuseram-se quatro grupos de informantes-chave que vivenciaram a realidade no período em estudo: (1) gestores (quatro em cada município); (2) mães enlutadas que haviam perdido algum filho na época do estudo (sete em cada município); (3) agentes de saúde (quatro em um município e oito em outro); (4) mãe vizinha (sete em cada um). Para compor o grupo de atores-informantes que exerciam papéis na gestão pública, os gestores, no período em estudo, foram escolhidos os dois prefeitos e secretários de saúde, os diretores dos hospitais públicos que atendiam na área da criança e os respectivos coordenadores do PACS. Os grupos compostos pelas mães que perderam algum filho $<1$ ano e pelos agentes de saúde foram constituídos a partir da busca nos registros dos óbitos junto aos relatórios dos agentes de saúde de cada município. Já o grupo das mães vizinhas, é composto por mulheres morando do lado das mães enlutadas que, nos anos estudados, tinham algum filho $<1$ ano. Os dados foram colhidos através de entrevistas semiestruturadas, com quatro eixos temáticos norteadores: (1) conceito e definição da mortalidade infantil; (2) origem do saber sobre a mortalidade infantil; (3) fatores determinantes da mortalidade infantil; (4) intervenções para a diminuição da mortalidade infantil.

Para o melhor entendimento, principalmente nos grupos de mães e vizinhas, perguntamos: "O que você entende por mortalidade infantil? Onde você ouviu e ouve falar sobre mortalidade infantil?", "Para você, o que causa a morte de crianças pequeninas, com < 1 ano de idade?", "Na gestão passada, do Prefeito [nome], em sua opinião, algo aconteceu que possa ter diminuído a morte de crianças pequeninas, das crianças com < 1 ano de idade?".

As entrevistas foram gravadas, transcritas e seu conteúdo organizado e classificado dentro dos seis eixos temáticos anteriores, por tipo de informante e município. Nessa publicação, analisamos o conteúdo e discutimos quatro categorias analíticas 20: a expressão "mortalidade infantil”, determinantes da mortalidade infantil, intervenções percebidas como efetivas na redução da mortalidade infantil e práxis educativa utilizada pelos programas de saúde implantados. A última, práxis educativa, emergiu do acervo da pesquisa, sendo uma categoria empírica que se destacou.

A pesquisa, vinculada ao projeto com bolsa de produtividade em pesquisa do CNPq (Conselho Nacional de Desenvolvimento Científico e Tecnológico), aprovado pelo Comitê de Ética em Pesquisa da Universidade de Fortaleza, atende 
aos princípios éticos preconizados pela $R e$ solução $n^{\circ}$. 196/1996 do Conselho Nacional de Saúde.

\section{Resultados e discussão}

Significado da expressão "mortalidade infantil"

Percebe-se que os atores tiveram, direta ou indiretamente, contato com a expressão "mortalidade infantil". Todos relataram que era um termo que muito se ouvia nos meios de comunicação. De certo, um reflexo da intensa mobilização em favor do combate à mortalidade infantil, capitaneada pela Secretaria Estadual de Saúde com o apoio da UNICEF 21.

Para os gestores, a dicção técnica "mortalidade infantil", é definida como "indicador de saúde". Entendem a taxa de mortalidade infantil como reflexo do desempenho e reputação profissional. A visibilidade deste "indicador" - publicado em boletim oficial - expõe ao estresse o gestor local. Baixar a taxa de mortalidade infantil se torna "uma meta" a ser cumprida a qualquer custo, sob pressão política contundente. Dr. Carlos, médico-gestor (Ma), relata que sentiu "uma exigência muito grande para não deixar a criança com menos de um ano morrer". Outro gestor (Ma) revela: “Quando um município tem uma taxa de mortalidade infantil alta, ele é mal visto... Irá deixar de vir recursos. Existe uma meta para reduzir essa mortalidade. Quando o município dá um acréscimo, ele é chamado atenção... mandam técnicos para ver o que está acontecendo". Dr. Irineto, médico-gestor $(\mathrm{Mb})$, revela que o governo estadual fez "uma campanha dirigida só com essa finalidade: reduzir a mortalidade infantil".

Segundo a literatura da época, havia um compromisso internacional do Brasil para o cumprimento de metas, especificamente de redução de $50 \%$ da taxa de mortalidade infantil até o ano 2000, compromisso que, pela legislação brasileira, em última análise, deveria ser executado pelos municípios 22. Sobre os ombros dos gestores municipais estava, não apenas o compromisso com a vida, mas, sobretudo, a responsabilidade de garantir uma Declaração Pública assinada pelo governo brasileiro.

Para os agentes de saúde a expressão "mortalidade infantil” também representa uma avaliação do seu desempenho profissional. Até para Catarina, agente de saúde (Ma), falar disto produz medo e estresse: “... isso já aconteceu [arbitrariedades por partes dos gestores]... isso não vai me prejudicar [falar sobre esse assunto]?”. Os agentes de saúde entendem a expressão morta- lidade infantil como uma obrigação, ação impositiva inerente a sua profissão. Olga, agente de saúde (Ma) aponta: “Toda reunião que tinha era para cuidar da mortalidade infantil... A gente tem de acompanhar a criança desde quando nasce até um ano... é ó que a gente mais fala e aconselha".

As mães-vizinhas, mais próximas da experiência da morte infantil, não têm familiaridade com a dicção técnica "mortalidade infantil", embora todas já tivessem "ouvido falar" pelos meios de comunicação. Relata Cristiana, mãe vizinha (Ma): "mortalidade infantil... não sei bem o que é. Já ouvi falar na televisão”. Algumas falam na "morte de crianças" e "doença que mata as crianças".

Para as mães que perderam filho, a mortalidade infantil expressa um sofrimento. Representa “um anjinho que custa esquecer!", disse Celiane (Mb). É com pesar que ela fala da morte da filha: “A bichinha adoeceu de diarréia... tinha gemedeira, dor de cólica... foram 17 dias de sofrimento, dia e noite, direto... vendo a minha menininha acabar!". "O que eu entendo", disse Francisca $(\mathrm{Mb})$, que perdeu o filho de quatro meses, "é que as crianças tão morrendo fácil”. Fafá, mãe enlutada (Ma), num lugarejo rural sem água encanada, fossa ou banheiro, disse: "já ouvi falar da mortalidade infantil. Na televisão é só que fala! São as crianças que nascem e morrem".

Nations 11, entrevistando mães enlutadas no Ceará, na mesma época, revela que a morte de crianças era expressa como "desespero", "sofrimento" e "anjinho”. São percepções e sentimentos que pouco aparecem nos discursos dos gestores e agentes de saúde.

\section{Determinantes da morte infantil}

Os gestores reconhecem determinantes macro socioeconômicos como "a pobreza", "a falta de água tratada”, “a desnutrição”. Eles reconhecem que a mortalidade infantil está associada ao problema social e à educação. Para este grupo de atores, mais afeito ao discurso científico dominante, a determinação social da mortalidade infantil trata-se de uma verdade clássica dentro da saúde pública 23 .

Contudo, a maioria, relaciona, estreitamente, a morte às supostas características dos pais: “ $A$ morte acontece mais em crianças subnutridas $e$ com pais ignorantes" (gestor Mb). Barros et al. 24, analisando a política de saúde no Brasil na mesma época desta pesquisa, descrevem que apesar da vigência do paradigma da multicausalidade e determinação social das doenças, na prática, ainda persiste uma visão reducionista, utilizando-se de modelos unicausais, como a teoria dos germes e a do estilo de vida. 
O agente de saúde culpa, também, os pais em condição de pobreza pela morte. Júlia, agente de saúde $(\mathrm{Mb})$ justifica: "Morre... porque os pais não têm condições ou então não ligam, né?". Tati, agente de saúde (Ma) diz: "As mães não ligam de tratar as crianças”. Outros associam a falência precoce à vulnerabilidade da criança empobrecida. Marta, agente de saúde (Mb), explica: “ $A$ criança pequena morre porque é sem defesa e adoece... quanto menor, a defesa é menor". Jandira, agente de saúde $(\mathrm{Mb})$, revela o impacto danoso da pobreza na saúde familiar: "Eu conheço um lugar ali... Lá só existe doença porque todo mundo é pobre demais!" Fatinha, agente de saúde (Ma), revela que há comunidades em que as crianças " não têm nem uma chinelinha pra calçar".

As mães vizinhas destacam como determinante da mortalidade infantil fatores macroestruturais ("a pobreza") e sobrenaturais ("a vontade de Deus”) - ambos estando além dos seus controles. Preta, mãe vizinha $(\mathrm{Mb})$, responsabiliza a dureza da vida na pobreza: "pra mim, pra uma pessoa que é pobre... em tudo falta. A gente que é pobre não pode comprar tudo enquanto. Não tem um aparelho sanitário..." Apoiadas no catolicismo popular e na forte crença na providência divina, buscam uma explicação espiritual para dar sentido à perda precoce. Assunção, vizinha (Mb), diz: "Se o pequeninho morrer, tinha de morrer mesmo... porque a gente cuida, viu!”. Ela se junta à vizinha enlutada, falando " $a$ gente" - em defesa da reputação da mãe sofrida. Também Elisângela, vizinha (Ma), se inclui dizendo: "Às vezes a gente não sabe como é que começa se é pela comida mal feita ou se é falta de comida". Poucas mães vizinhas apontam "a falta de higiene" e "o descuido dos pais" pela morte. O enfoque nos fatores comportamentais da mãe parece originar-se do discurso hegemônico do profissional de saúde. Maria (vizinha $\mathrm{Mb}$ ) explica: “às vezes acontece por causa da sujeira em casa... Eu lhe digo porque o médico diz pra gente!"

As mães enlutadas, por sua vez, denunciam determinantes sociais pela morte dos filhos: a pobreza, as desigualdades, a falta de alimentos. Branca, mãe enlutada (Ma), revela que o problema é de tanto "passar fome". Severina (Ma) revela que o grande problema é a falta de dinheiro para dar o que a criança precisa: "não tem todo dia, aqui acolá a gente ganha”. Cássia, mãe enlutada $(\mathrm{Mb})$, denuncia as desigualdades entre ricos e pobres: "a doença mesma chega mais na criança pobre, pela falta de condições. É, aí, todo mal tratado. Se cair no chão, deixa, né? Fica se arrastando, uma criança pega uma poeira, se joga por aí. As vezes a mãe não tá em casa, não tem tempo. Hoje, quem sabe por quanto lugar eu já andei, né? Meus filhos tão aí. Quando eu chego é do jeito que Deus quiser! As vezes, eu saio de casa deixo [os filhos] bom, quando chego tá doente, porque eu não tenho condição!”. As mães do município com pior indicador enfatizam problemas no acesso à assistência médica. Julinha, mãe enlutada (Mb), denuncia a discriminação da criança pobre no hospital público: "Morre devido tudo isso que falta. Se leva pra um hospital, quando chega lá, porque a gente é pobre, não é bem tratada... Porque é filho de pobre num sabe nem de que é que morreu... Só atende na hora certa quem é rico!" Em tom ressentido, Cássia (Mb) revela essa injustiça: "Filho do rico é assim? É não! A condição dele é outra. E, eu acho que pobre adoece mais $e$ morre mais".

Essa subjetividade, expressa nos discursos sobre os determinantes, revela sentimentos, pensamentos e concepções, diferenciando claramente os grupos de atores, ao mesmo tempo em que sugere uma diversidade de intenções em relação às intervenções a serem implementadas 25 . Percebe-se, como Good 15, que a "heteroglossia", a multiplicidade de vozes sobre a experiência humana, não somente diverge, mas, frequentemente, é contestada pelo discurso e prática hegemônica da Biomedicina. É preciso reunir estas múltiplas e divergentes percepções para enxergar o evento social, pois nenhuma perspectiva poderia sozinha revelar completamente a realidade.

\section{Intervenção para a redução da mortalidade infantil}

No município que alcançou maior redução da mortalidade infantil, o compromisso do prefeito com a redução da mortalidade infantil foi um fator marcante. Como profissional de saúde (Ma), ele abraçou "essa causa" entusiasticamente: "fiz campanha dirigida só com essa finalidade: diminuir a taxa de mortalidade infantil! Eu sabia o que era importante e se tratava de um compromisso pessoal". Obstinadamente, implantou medidas eficazes: soro caseiro, monitoramento de crescimento, exames de pré-natal, incentivo ao aleitamento materno, diagnóstico e tratamento precoce das infecções respiratórias agudas. Dr. Paulo, médico-gestor (Ma), afirma que houve um apelo emotivo à população para participar do movimento: "todo mundo estava trabalhando para diminuir a taxa de mortalidade infantil".

Neste município, os gestores destacam o interesse, desejo, conhecimento técnico, enfim, o comprometimento político do prefeito-médico como fator decisivo - condição para o desenvolvimento em saúde 26 -, enquanto culpabiliza a mãe e sua "ignorância” pela morte precoce. Essa atitude de deslocar o lócus da responsabilidade social pelas mortes infantis foi discutida por $\mathrm{Na}$ - 
tions 27 em estudo das mortes infantis evitáveis no Ceará. Dr. Carlos, médico-gestor (Ma), fala da pressão que sofreu: “Estava tendo uma pressão muito grande para que nós diminuíssemos a taxa de mortalidade infantil". Instituídos de poder punitivo, os gestores se sentiam autorizados a usarem da força legal - tomar medidas drásticas até contra a vontade da família - para atingir sua meta. "Tivemos que ir atrás do juiz para internar a criança!” - afirma outro gestor (Ma).

Os gestores do município "mal-visto" (Mb) justificam o péssimo desempenho no combate à MI pela falta de recursos orçamentários: "Para um município pobre... o cofre público sem dinheiro... sem uma assistência básica, é muito fácil ter uma alta taxa de mortalidade infantil". O Prefeito do município "mal-visto", comerciante local, não acredita em medidas médico-assistenciais. Centraliza sua atenção nas questões financeiras do município, encarando a intervenção do Governo Estadual para reduzir a mortalidade infantil como um peso orçamentário: “O problema é que o orçamento é pouco, não dá pra fazer nada com pouco dinheiro".

Para os agentes de saúde do município com melhores resultados (Ma), são o aumento no atendimento médico e o trabalho dos próprios agentes os responsáveis pela queda na taxa de mortalidade infantil: "É o nosso trabalho que é muito válido... com ajuda do Secretário de Saúde... que é muito bom para a gente e a nossa coordenadora". Amélia, outro agente (Ma), acentua: "Quem mais fez para diminuir a mortalidade infantil é o Agente de Saúde. Tenho certeza!"

Ao contrário, os agentes de saúde do município "mal visto" (Mb) acusam a falta de compromisso do gestor municipal para implementar uma política para reduzir a mortalidade infantil. Uma agente indignada afirma: "A gente nem sabia quem era o Secretário de Saúde!”.

As mães vizinhas do município de melhores indicadores (Ma), como os agentes de saúde, enfatizam que houve melhora no acesso ao atendimento médico: "É mais fácil salvar um menino doente porque tem posto [de saúde] em todo canto... facilitou muito pra gente... Médico não tinha antes!". Informação também relatada pelos agentes de saúde do mesmo município. O que pode ser corroborado pela análise da produção ambulatorial em atenção básica nos anos 90, que revela um aumento de consultas médicas em muitos municípios do Nordeste neste período, mesmo que de forma irregular 29. Outras vizinhas destacam a melhoria na qualidade do atendimento: “Antes, eu me queixava é do atendimento... agora, não!”. Algumas mencionam o trabalho do agente, a merenda escolar em creches e a doação de medicamentos. "Teve também o trabalho do Agen- te... Era mais alimento pros bichinhos na creche... mais fácil pegar remédio, né?".

As mães vizinhas do município de piores indicadores $(\mathrm{Mb})$ não relataram nenhuma ação para a queda na taxa de mortalidade infantil. “ $A$ mortalidade infantil diminuiu, sim, porque eu escuto nos jornais... mas não sei por que", disse a vizinha Júlia. Reclamam da falta de acesso ao atendimento médico próximo de casa: "médico é muito difícil aqui... às vezes vai para o hospital e volta porque não tem médico".

As mães enlutadas não identificam uma intervenção específica para a diminuição da mortalidade infantil. Nesse universo moral, é Deus protetor que obra milagres e não o governante: “quando Deus não quer levar, ele mostra o remédio. Mas, quando quer para ele, não tem remédio que cure... nem médico... nem nada!" (Ma). Se um filho sobrevive, é uma "bênção de Deus" (Ma). O poder divino decide a hora de morrer, como encara Socorro (Ma), sofrendo a perda da filhinha: "eu acho que era por causa que ela não era para ser meu... não foi falta de cuidado”. O discurso das mães enlutadas dos municípios desqualifica de forma contundente a ação governamental. "Foi feito nada não... ontem mesmo receitei meu filho, mas ta aqui a receita dentro da bolsa. Não comprei o remédio porque não pude. Tive que comprar o de cumer pra comer" $(\mathrm{Mb})$.

\section{Caráter das práticas educativas}

Em ambos os municípios, as práxis educativas em saúde, a partir do discurso colhido nas entrevistas, revestem-se de um caráter autoritário, impositivo e estigmatizante. Onde o papel do educador, em geral, é de "botar na cabeça" dos pais as normas de higiene e medidas de cuidado; o dever dos pais é de assimilar tudo: " $a$ obrigação deles é dar ouvido às informações que a gente passa... A mãe tem que botar na cabeça que tem que fazer" (agente de saúde Ma). O profissional transmite informações a serem assimiladas: "temos que elevar o nível educacional, pois só assim irá conseguir com que essa população assimile tudo aquilo que ela tem que fazer" (gestor $\mathrm{Mb}$ ).

Paulo Freire 29 (p. 21), em seu clássico livro Pedagogia da Autonomia: Saberes Necessários à Prática Educativa, é muito contundente contra este tipo de educador: "A grande tarefa do sujeito que pensa certo não é transferir, depositar, oferecer, doar ao outro, tomado como paciente de seu pensar, a inteligibilidade das coisas, dos fatos, dos conceitos".

Esta práxis de "botar na cabeça" dos "pais ignorantes” conhecimentos técnico-científicos é internalizada, frequentemente, pela população como uma violência institucional, à semelhança 
do que relata Gomes et al. ${ }^{3}$, quando estudaram a experiência de internação em hospitais públicos no Ceará. Freire 30 , em seu livro Pedagogia do Oprimido, criticou essa educação chamando-a de concepção e prática "bancária" da educação; por transformar os "educandos" em "quase coisas", "recipientes" onde se deposita "conhecimentos". Uma prática educativa que minimiza sobremaneira o poder criador da população e que, "quanto mais se lhes imponha passividade, tanto mais ingenuamente, em lugar de transformar, tendem, a adaptar-se ao mundo, à realidade parcializada nos depósitos recebidos" 30 (p. 34).

Percebe-se claramente que este tipo de educação em saúde transformou-se em uma "batalha" agressiva, como relata a agente de saúde, Juliete (Ma): “A gente vive pelejando, batalhando, né? Toda casa que a gente chega é a gente pelejando pras pessoas fazerem higiene... cuidarem dos seus filhos". Longe de empoderar a mãe de família, ela é transformada numa adversária. Aquela mãe que não adere à práxis autoritária é estigmatizada como sendo "teimosa", "atrevida" e "desobediente". "É a mãe que é muito teimosa... não quer fazer o que a gente manda" - reclama outra agente $(\mathrm{Mb})$. Em última instância, o profissional busca respaldo judicial e policial para forçar a mãe a cumprir sua ordem: "Quando a gente não consegue convencer a mãe... tem que ir atrás do juiz... a gente pede o apoio do conselho tutelar. Se ela queira ou não... a mãe terá que cumprir as orientações!" (agente de saúde - Ma).

Outras pesquisas, em décadas mais recentes, realizadas também no Ceará 31 e em Santa Catarina 32 argumentam que os profissionais da ESF ainda utilizam de forma hegemônica práticas impositivas, unidirecionais, típicas da perspectiva "bancária”. São práticas que, por não contribuírem para a produção social da saúde e a democratização do conhecimento do processo saúde-doença, ferem os próprios objetivos estabelecidos pelo Ministério da Saúde para a ESF 33 .

O discurso dos gestores traz consigo uma clara culpabilização dos pais pobres em relação à situação de morte. “A morte dessas crianças se dá devido à falta de cuidados dos pais, por falta de alimentação, porque quem morre mais é a criança desnutrida" - diz um gestor (Ma). Freire 30 (p. 35), falando sobre a visão "bancária” da educação em situações de iniqüidade, relata que "os oprimidos" são considerados "como casos individuais, são patologias da sociedade sã, que precisa, por isto mesmo, ajustá-los a ela, mudando-lhes a mentalidade de homens ineptos e preguiçosos".

Atualmente, mesmo que a prática participativa seja vista como fator essencial para a produção de mudanças sociais ${ }^{34}$ e que a política nacional de promoção da saúde defenda a am- pliação da autonomia e a co-responsabilidade de sujeitos e coletividades, os profissionais de saúde continuam adotando uma práxis incongruente com esta orientação 35,36. Note-se que Gazzinelli et al. 36, analisando os documentos publicados entre 1980 e 1992 pelo Ministério da Saúde, praticamente uma década antes do período aqui estudado, reconhecem que houve, ao longo dos anos, um processo nítido de mudança em relação à opção educativa proposta; saindo de uma "educação em saúde" marcada por um discurso coercitivo, normativo e que desconsiderava a desigualdade social dos sujeitos, para uma abordagem fortemente influenciada pela "teoria da educação libertadora” de Freire ${ }^{36}$.

Tais achados refletem precipuamente um conflito entre o que é proposto pelo Ministério da Saúde e o que a formação destes médicos e enfermeiros, responsáveis pela capacitação dos agentes de saúde e pela implantação das políticas “prescritas” pelo Ministério da Saúde, apresenta. Profissionais de saúde, em sua grande maioria, saídos de universidades com pouca formação humanística 37 , que não tiveram uma formação pedagógica e antropológica, incorrem frequentemente no erro de desconsiderar as diferenças culturais, sociais e de origem da população, pensando que suas idéias são as mais evidentes e corretas. Haja vista a grande limitação do olhar biomédico, com sua visão reducionista 36 , em perceber o que o filósofo francês Morin 38 chamará "a complexidade humana”. A conseqüência é o que foi identificado, uma educação normativa, como bem argumenta Morin 38 (p. 43): "É uma inteligência míope que acaba por ser normalmente cega... Incapaz de considerar o contexto e o complexo planetário, a inteligência cega torna-se inconsciente e irresponsável".

Os agentes de saúde revelam que as famílias têm ficado resistentes à suas orientações, ignorando as instruções e conselhos: "o pessoal não quer mais dar atenção... Na maioria da parte, a gente passa a informação e o pessoal não ligam... não dão ouvido às informações que a gente faz" (Agente de Saúde - Ma). Algumas mulheres, como forma de resistência, mentem para o profissional. Olga, agente de saúde (Ma), relata que "a mãe mentia" quando era perguntada "se ela tava dando só mama...", pois as vizinhas “diziam que ela dava também outro alimento". À semelhança do encontrado em outras pesquisas 3,39 sobre intervenções de saúde em populações empobrecidas, a resistência surge provavelmente como uma estratégia que a população usa para enfrentar o desprezo do profissional e sua práxis autoritária.

Por outro lado, foi marcante a capacidade de superação dos conflitos entre as famílias e os 
profissionais de saúde. Apesar de todas as dificuldades socioeconômicas, nos relatos das mães enlutadas e vizinhas, o know-how da família ou sua resiliência 40 apresenta-se como impulsionador da procura de atendimento médico para levar a saúde aos seus filhos. Neste sentido, o educador Freire 29 (p. 13) nos lembra da capacidade da população para aproveitar conhecimentos mesmo que provenientes do "ensino bancário" e "dar, como se diz na linguagem popular, a volta por cima e superar o autoritarismo e o erro epistemológico do bancarismo". Tal referência freirirana - a capacidade dos seres humanos de ir além de seus condicionamentos - talvez explique porque no município em que a educação em saúde foi mais presente, mesmo que do tipo "bancária”, tivemos melhores resultados. Contudo, Freire 29 (p. 14) também afirma que "isto não significa, porém, que nos seja indiferente ser um educador bancário ou um educador problematizador".

Portanto, os achados podem revelar uma crise, não do programa de combate à mortalidade infantil, mas de sua práxis educativa, quando os gestores desconsideram que a grande tarefa, segundo a mesma referência freiriana 29 (p. 21), é "desafiar o educando com quem se comunica $e$ a quem comunica, produzir sua compreensão do que vem sendo comunicado. Não há inteligibilidade que não seja comunicação e intercomunicação e que não se funde na dialogicidade. O pensar certo por isso é dialógico e não polêmico". Do mesmo modo, em decorrência desta práxis educativa não dialógica, revela uma crise do PACS, já que está a divergir totalmente do princípio da integralidade inscrito no SUS 41 .

\section{Considerações finais}

Esta pesquisa procurou apresentar, através dos discursos de diferentes atores - da multivocalidade - contribuições para o entendimento da diferença do decréscimo da mortalidade infantil entre os municípios estudados. Percebe-se que nenhuma perspectiva única pôde abarcar a realidade completa da redução da mortalidade infantil no Ceará. Contudo, a abertura para múltiplas perspectivas possibilita a ação criativa, podendo emergir um novo pensar e agir em saúde.

Este estudo chama a atenção para a grande atuação do Governo Federal e da Secretaria de Saúde do Estado do Ceará no controle da mortalidade infantil na década de 1990. A comparação entre o município de maior e menor redução nas mortes na infância desvela a influência da vontade política do gestor municipal em implantar intervenções e ações educativas que visavam a redução da mortalidade infantil. De tal forma que o município que teve melhor desempenho na redução da mortalidade infantil foi onde mais se relatou o aumento da assistência médica; foi também onde houve um melhor e mais efetivo controle-cobrança e supervisão das atividades educativas desenvolvidas pelos profissionais de saúde.

Embora seja fator relevante a capilaridade alcançada pelo discurso oficial, através dos meios de comunicação e dos agentes de saúde, identificou-se, entre os diversos grupos de atores, uma grande diferença na percepção da morte de crianças menores de um ano, bem como das intervenções efetivadas.

A práxis educativa utilizada pelos programas de saúde, em ambos os municípios, revelou um marcante caráter impositivo que não favorece a autonomia. Mesmo atingindo suas "metas", foi forte o discurso que culpabiliza e criminaliza a própria mãe enlutada, principalmente no município de maior redução da mortalidade infantil. Assim, tem ensejado na população atitudes de resistência. O que o discurso revela, contudo, é que a população assimila os avanços técnicos para reduzir a morte de crianças - provavelmente, um reflexo da resiliência familiar $34 \mathrm{ou}$, como Freire 29 argumenta, a capacidade dos seres humanos de ir além dos condicionamentos.

Percebe-se, também, que esta práxis educativa provocou, junto à população, uma rejeição ao PACS. O que sublinha ainda mais que, apesar do êxito na redução da taxa de mortalidade infantil, não se pode ficar indiferente à opção educativa utilizada.

Remete-se à necessidade de políticas públicas de saúde subsidiadas por abordagens pedagógicas e antropológicas que promovam a autonomia e "empoderamento" da pessoa humana. Deve ser realmente revista a forma de operacionalizá-las, principalmente no tocante aos processos de trabalho e à prática educativa. Isso implica inclusive na mudança das políticas pedagógicas dos cursos de graduação que formam os profissionais que irão se inserir no SUS.

Chama a atenção para que seja dada importância, tanto quanto à queda da taxa de mortalidade infantil, à busca de uma revolução das políticas públicas, onde as vozes dos mais próximos da experiência de morte de crianças sejam ouvidas e a prática profissional seja iluminada por uma ética humana do cuidado. 


\section{Resumo}

Esta pesquisa qualitativa investiga as percepções de diversos atores sociais sobre a mortalidade infantil e o programa para sua redução no Ceará, Nordeste brasileiro. Analisam-se dois municípios que tiveram entre 1993 e 1997 comportamento oposto em relação a este indicador de saúde - época em que o estado se destaca internacionalmente pela redução das mortes infantis. Através de 48 entrevistas semiestruturadas com quatro grupos de informantes-chave-gestores, agentes comunitários de saúde, mães que perderam filho e vizinhas com filho na mesma faixa etária - e análise de conteúdo, revela-se uma "multivocalidade" conflitante sobre a temática. Embora, a vontade política dos gestores de implantar as intervenções seja divergente entre os municípios, as diferenças nas percepções acerca da morte infantil são mais marcantes entre os grupos de atores, independentemente do município. Observa-se uma prática educativa autoritária que prejudica a aceitação do Programa de Agentes Comunitários de Saúde. É preciso políticas públicas que dêem voz às pessoas próximas da experiência da morte infantil.

Mortalidade Infantil; Educação em Saúde; Política de Saúde; Desenvolvimento de Programas; Antropologia

\section{Colaboradores}

J. R. P. Sousa idealizou o estudo, coletou e analisou os dados e redigiu o artigo. M. Nations orientou a coleta dos dados, participou na organização do artigo, analises de dados e redação do texto.

\section{Agradecimentos}

M. Nations agradece apoio de Conselho Nacional de Desenvolvimento Científico e Tecnológico (CNPq), projeto no. 478791/2003-8, Anjos Com Azas Molhadas Não Voam: Uma Crítica da Teoria da Negligência Materna e o Cuidado Infantil no Nordeste Brasileiro. Também, uma bolsa CNPq de pós-doutorado na Escola de Medicina, Universidade de Harvard, Departamento de Saúde Global e Medicina Social (2007-2008), permitiu uma reflexão aprofundada sobre a mortalidade infantil no Ceará. J. R. P. Sousa agradece a colaboração de pesquisadores e professores do Departamento de Saúde Comunitária e do Núcleo de Estudos em Saúde coletiva, Universidade Federal do Ceará por contribuições na operacionalização desta pesquisa.

\section{Referências}

1. Svitone EC, Garfield R, Vasconcelos MI, Craveiro VA. Primary health care lessons from the Northeast of Brazil: the Agentes de Saúde Program. Rev Panam Salud Pública 2000; 7:293-301.

2. Nations MK, Gomes AMA. Cuidado, "cavalo batizado" e crítica da conduta profissional pelo paciente-cidadão hospitalizado no Nordeste brasileiro. Cad Saúde Pública 2007; 23:2103-12.

3. Gomes AMA, Nations MK, Luz MT. Pisada como pano de chão: experiência de violência hospitalar no Nordeste Brasileiro. Saúde Soc 2008; 17:61-72.

4. Faheina RC. Assassinatos de mulheres: números crescem no Cariri. Jornal O Povo 2006; 15 mai.

5. Souza ACT, Cufino E, Perterson KE, Gardner J, Amaral MIV, Ascherio A. Variation in infant mortality rates among municipalities in the state of Ceará, Northeast Brazil: an ecological analysis. Int J Epidemiol 1999; 28:267-75.
6. Secretaria da Saúde do Governo do Estado do Ceará Informações em saúde: situação de saúde. Ceará: mortalidade. http://www.saude.ce.gov.br/site/in dex.php?option=com_content $\&$ view=article \&id $=$ 157\&Itemid=211 (acessado em 18/Ago/2009).

7. Bezerra JG, Kerr-Pontes LRS, Barreto ML. Mortalidade infantil e contexto socioeconômico no Ceará, Brasil, no período de 1991a 2001. Rev Bras Saúde Mater Infant 2007; 7:135-42.

8. Duarte CMR. Reflexos das políticas de saúde sobre as tendências da mortalidade infantil no Brasil: revisão da literatura sobre a última década. Cad Saúde Pública 2007; 23:1511-28.

9. Fundo das Nações Unidas para a Infância. Situação mundial da infância 2008. Brasília: Fundo das Nações Unidas para a Infância; 2008. (Caderno Brasil). 
10. Sousa TRV, Leite PAM. Análise por dados em painel do status de saúde no Nordeste Brasileiro. Rev Saúde Pública 2008; 42:796-804.

11. Nations M. Corte a mortalha: o cálculo humano da morte infantil no Ceará. Rio de Janeiro: Editora Fiocruz; 2009.

12. Silva LMV, Costa MCN, Paim JS, Dias IB, Cunha ABO, Guimarães ZA, et al. Brechas redutíveis de mortalidade em capitais brasileiras (1980-1998). Inf Epidemiol SUS 2002; 11:245-7.

13. Ministério da Saúde. Informações de Saúde. Coeficiente de mortalidade infantil por ano segundo regiões e unidades da Federação. Brasil, 1989 a 1998. 2000. http://tabnet.datasus.gov.br/cgi/mortinf/ mibr.htm (acessado em 02/Jul/2010).

14. Serapioni M. Métodos qualitativos e quantitativos na pesquisa social em saúde: algumas estratégias para a integração. Ciênc Saúde Coletiva 2000; 5:187-92.

15. Good BJ. Medicine, rationality and experience: an anthropological perspective. Cambridge: Cambridge University; 1994.

16. Morin E. Introdução ao pensamento complexo. Lisboa: Instituto Piaget; 1991.

17. Minayo MCS. Abordagem antropológica para avaliação de políticas sociais. Rev Saúde Pública 1991; 25:233-8.

18. Bezerra Filho JG, Pontes LRFSK, Miná DL, Barreto ML. Mortalidade infantil e condições sociodemográficas no Ceará, em 1991 e 2000. Rev Saúde Pública 2007; 41:1023-31.

19. Barreto ICHC, Pontes LK, Correa L. Vigilância de óbitos infantis em sistemas locais de saúde: avaliação da autópsia verbal e das informações de agentes de saúde. Rev Panam Salud Pública 2000; 7:303-12.

20. Quivy R, Campenhaudt LV. Manual de investigação em ciências sociais. 5ạ Ed. Lisboa: Gradiva Publicações; 2008.

21. Barros F. Pobreza, desnutrição e mortalidade infantil: condicionantes sócio-econômicos. Cad Saúde Pública 1993; 9 Suppl 1:114-7.

22. Simões CCS. Perfis de saúde e de mortalidade no Brasil: uma análise de seus condicionantes em grupos populacionais específicos. Brasília: Organização Pan-Americana da Saúde; 2002.

23. Krieger N. Theories for social epidemiology in the 21st century: an ecosocial perspective. Int J Epidemiol 2001; 30:668-77.

24. Barros ME, Piola SF, Vianna SM. Política de saúde no Brasil: diagnóstico e perspectivas. Brasília: Instituto de Pesquisa Econômica e Aplicada; 1996. (Texto para Discussão, 401).

25. Ortner SB. Subjetividade e crítica cultural. Horizontes Antropológicos 2007; 13:375-405.

26. Coura JR. Endemias e meio ambiente no século XXI. Cad Saúde Pública 1992; 8:335-41.

27. Nations MK. Infant death and interpretive violence in Northeast Brazil: taking bereaved Cearense mothers' narratives to heart. Cad Saúde Pública 2008; 24:2239-48.
28. Costa MCN, Mota ELA, Paim JS, Silva LMV, Teixeira MG, Mendes CMC. Mortalidade infantil no Brasil em períodos recentes de crise econômica. Rev Saúde Pública 2003; 37:699-706.

29. Freire P. Pedagogia da autonomia: saberes necessários à prática educativa. Rio de Janeiro: Editora Paz \& Terra; 1996.

30. Freire P. Pedagogia do oprimido. 23a Ed. Rio de Janeiro: Editora Paz e Terra; 1994.

31. Silva CP, Dias MAS, Rodrigues AB. Práxis educativa em saúde dos enfermeiros da Estratégia Saúde da Família. Ciênc Saúde Coletiva 2009; 14 Suppl 1:1453-62.

32. Besen CB, Souza Netto M, Ros MA, Silva FW, Silva GG, Pires MF. A estratégia saúde da família como objeto de educação em saúde. Saúde Soc 2007; 16:57-68.

33. Coordenação de Saúde da Comunidade, Secretaria de Assistência à Saúde, Ministério da Saúde. Saúde da Família: uma estratégia para a reorientação do modelo assistencial. Brasília: Ministério da Saúde; 1997.

34. Bursztyn I, Ribeiro JM. Avaliação participativa em programas de saúde: um modelo para o Programa de Saúde do Adolescente. Cad Saúde Pública 2005; 21:404-16

35. Secretaria de Vigilância em Saúde, Ministério da Saúde. Política nacional de promoção da saúde. Brasília: Ministério da Saúde; 2006. (Série B. Textos Básicos de Saúde)

36. Gazzinelli MF, Gazzinelli A, Reis DC, Penna CMM Educação em saúde: conhecimentos, representações sociais e experiências da doença. Cad Saúde Pública 2005; 21:200-6.

37. Caprara A. Uma abordagem hermenêutica da relação saúde-doença. Cad Saúde Pública 2003; 19:923-31.

38. Morin E. Os sete saberes necessários à educação do futuro. 2a Ed. São Paulo: Cortez Editora/Brasília: Organização das Nações Unidas para a Educação a Ciência e a Cultura; 2000.

39. Chiaravalloti NF, Baglini V, Cesarino MB, Favaro EA, Mondini A, Ferreira AC, et al. O Programa de Controle do Dengue em São José do Rio Preto, São Paulo, Brasil: dificuldades para a atuação dos agentes e adesão da população. Cad Saúde Pública 2007; 23:1656-64

40. Yunes MAM, Garcia NM, Albuquerque BM. Monoparentalidade, pobreza e resiliência: entre as crenças dos profissionais e as possibilidades da convivência familiar. Psicol Reflex Crit 2007; 20:444-53.

41. Alves VS. Um modelo de educação em saúde para o Programa Saúde da Família: pela integralidade da atenção e reorientação do modelo assistencial. Interface Comun Saúde Educ 2004/2005; 9:39-52.

Recebido em 17/Jan/2010

Versão final reapresentada em 20/Out/2010 Aprovado em 26/Out/2010 